\title{
High Performance Work Practices Facilitating Employee Engagement: A Study of PSUs in Delhi NCR
}

\author{
Pooja Misra $^{\star}$ and Jaya Gupta ${ }^{\star}$
}

\begin{abstract}
The theme of employee engagement has generated a great deal of attention among human resource practitioners across the globe. Companies are increasingly focusing on means of creating and leveraging levels of employee engagement. Employee engagement was experimentally determined to be a key forecaster of desirable organizational outcomes such as customer satisfaction, retention, productivity and profitability. Research studies have suggested that high-performance work practices can help to develop positive beliefs and mind-set associated with employee engagement. These practices can, therefore, generate the kinds of discretionary behaviours that lead to enhanced performance. The present research attempts to analyse the relationship between high performance work practices, employee engagement and turnover intentions for public sector units (PSUs) in Delhi and NCR. The research is exploratory in nature and was conducted on the basis of self-completed questionnaires and relevant secondary sources.
\end{abstract}

Keywords: ability, employee engagement, high performance work practices, motivation, opportunity to participate, turnover intentions

\section{Introduction}

Employee engagement may be regarded as one of the foremost business priorities for senior executives in the organizations of the contemporary world. A highly engaged workforce is likely to increase innovation and productivity and, at the same time, reduce the costs related to hiring and retention in highly competitive talent markets. Business leaders are acknowledging the fact that it is essential to have a high-performing workforce for growth and survival. Research studies have suggested that high-performance work practices (HPWP) can help to develop positive beliefs and mind-sets associated with employee engagement. These practices can, therefore, generate the kinds of discretionary behaviours that lead to enhanced performance. The present study indicates that implementing HPWP can contribute to a great extent to attain a high level of employee engagement amongst managers.

\footnotetext{
$\star \quad$ Dr. Pooja Misra is Assistant Professor, Economics, at Birla Institute of Management Technology (BIMTECH), Greater Noida, India.

* Dr. Jaya Gupta is Assistant Professor at Birla Institute of Management Technology (BIMTECH), Greater Noida, India.
} 
In the current business environment, eliciting high performance from employees is crucial for organizational success. High performance from employees can be achieved by an organization by adopting human resource (HR) practices which enhance work performance and facilitate the development of a high performance work culture. In order to have effective HR management practices implemented in the organization, those practices need to be complementary to each other. Now, systems and processes may be duplicated. However, the competitive edge gained by companies ranking high in employee engagement cannot be duplicated and, consequently, this represents a distinctive factor. High levels of employee engagement are known to be associated with improved employee performance (Smythe, 2008; Walters, 2008; Chang, 2006; Crawford, 2006; Echols, 2005; Tasker, 2004; Luthans \& Peterson, 2002; Tritch, 2003). Employee engagement was experimentally determined to be a key forecaster of desirable organizational outcomes, such as customer satisfaction, retention, productivity and profitability (Buckingham \& Coffman, 1999). As per Gallup's research over the years, it has been established that less than $30 \%$ of the company workforce is truly engaged in its work; that is, $30 \%$ or less of employees work with passion and zeal and feel an immense connection to their companies.

Kahn (1990) has stated that as a function of the perception of the benefits that employees receive from a role, people vary in their engagement levels. Social exchange theory establishes the fact that a feeling of return on investments can come from factors such as significant work and extrinsic rewards and recognition. Compensation components, such as benefits, pay and incentives, produce value for the organization and its employees. Compensation, which was used as a reward for excellent job performance, has an impact on an employee's morale and job satisfaction. In social exchange theory, employees on receiving rewards and recognition from their organization feel obliged to respond and reciprocate with higher levels of engagement. Employees with a perception of higher levels of procedural and distributive justice are more likely to feel obliged to the organization and so perform their roles by putting in more discretionary effort and giving more of themselves through greater levels of engagement.

The present study attempts to study the relationship between HPWP and employee engagement. Employee engagement has been found to result in a range of positive outcomes, both at the individual and the organizational levels. Employee engagement may be regarded as a lever for business success since the engaged employees are likely to deliver higher productivity, lower absenteeism, less of a turnover intention, superior service quality, more satisfied and loyal customers, high job satisfaction, more commitment, increased organizational citizenship behaviour and improved bottom-line business results. Studies suggest that there are positive associations between employee engagement and performance. Wright, McMahan and McWilliams (1994) have suggested that HR practices may be regarded as the means through which employee perceptions, attitudes and behaviours are shaped. Hence, the HR practices of an organization may be regarded as having a significant impact in enhancing employee engagement. As stated by Joshi and Sodhi (2011), organizational policies, procedures, structures, and systems decide the extent to which employees are satisfied, committed or engaged in an organization. Employee satisfaction with the HR practices of the organization influence the level of engagement of employees.

A growing body of research provides strong support for the correlation relationship between high performance work systems and various 
positive outcomes for employees, organizations and their customers, which include higher productivity (Arthur, 1994; Huselid, 1995), profitability, customer satisfaction and retention (Hoque, 1999), better workplace safety (Zacharatos, Barling \& Iverson, 2005) and lower turnover, waste and inefficiency (Arthur, 1994). High performance work practices may be regarded as a coherent set of practices that augment the skills and expertise of the workforce, their participation in the decision making processes and motivation to put forth discretionary effort (Appelbaum et al., 2000). These in turn have been found to result in superior firm performance and sustainable competitive advantage (Way, 2002). In order to ensure achieving and sustaining high levels of performance requires a positive workplace environment and practices that develop and leverage employees' knowledge and ability to create value. HPWP have long been a subject of academic interest among HR professionals. They may be regarded as a combination of innovative HR practices which tend to maximize employee knowledge, skills and performance of the employees resulting in persistent performance improvements and subsequently in employee satisfaction and a sense of personal achievement. It has been observed that increased implementation of HPWP leads to better performing organizations in terms of financial and employee outcomes (Combs et al., 2006). When designed properly, these practices influence organizational performance to a considerable extent in order to attain synergies among practices and thereby facilitate the accomplishment of the organization's competitive strategy. The individual ability, motivation, opportunity to perform (AMO) model focuses on those HR practices that increase effective discretionary behaviour amongst employees. The idea in the AMO perspective is that human resource management (HRM) policies lead to mediating changes in employees' abilities, motivations and opportunities to participate that positively influence organizational performance. This has the effect of making workers feel more highly committed to their organization, their department, their colleagues and their job, while also being more willing to go the extra mile. In the model, effective discretionary effort is a function of the employees' abilities, motivation, and opportunity to participate (Appelbaum et al., 2000). Boxall and Purcell (2003) observe that according to the AMO model people perform well when "they are able to do so (they can do the job because they possess the necessary knowledge and skills)" (abilities); "they have the motivation to do so (they will do the job because they want to and are adequately incentivized)" ( motivation) and "their work environment provides the necessary support and avenues for expression (for example, functioning technology and the opportunity to be heard when problems occur)" (opportunity to participate).

The AMO Model, proposed by Appelbaum et al. (2000) and Bailey, Berg and Sandy (2001) suggests that improving the ability and skills of employees, motivating them and providing them with opportunities to participate could result in positive attitudinal and organizational outcomes. The three elements together contribute to building sustainable employee performance. These elements are firmly grounded in industrial psychology, work psychology and human capital theory. The HR systems which foster ability, motivation and opportunity to participate will be the more effective. Boxall and Purcell (2003) summarize the AMO Model as:

Performance $=\mathrm{f}($ employees' ability, motivation and opportunity to participate).

Empirical research in HRM (Lepak et al., 2006) suggests that, according to the AMO perspective, the HRM system of employees' ability to perform (e.g. selection, training, performance appraisal and career planning) influences their skills 
(competences, including cooperation), the HRM system of employees' motivation to perform (e.g. pay for performance, job security, work life balance and information sharing) influences their attitudes (motivation, commitment, satisfaction) and the HRM system of employees' opportunity to perform (participation in decision making, teamwork and autonomy) influences their behaviour (retention, presence).

Employee engagement and productivity, profitability, employee retention, safety and customer satisfaction have a statistical relationship between themselves (Buckingham \& Coffman, 1999; Coffman \& Gonzalez-Molina, 2002). Voluntary turnover creates a significant cost, both in terms of direct cost, such as finding a replacement and in terms of indirect cost, such as the extra work pressure on the remaining staff or the loss of social capital. Dysfunctional turnover, undesirable and excessive turnover can also result in building a negative brand image of the organization, both internal and external; thus, it is not surprising that voluntary turnover continues to attract the attention of scholars and practitioners alike. According to researchers such as Fishbein and Ajzen (1975), intentions to leave the organization are important determinants of actual behaviour.

Numerous researchers (e.g. Price \& Mueller, 1981; Saks, 2006) have attempted to answer the question of what determines people's turnover intention by investigating possible previous circumstances that led to employees' intentions to quit. Research suggests that pay and benefits, equality of opportunity, fairness of treatment and job satisfaction were some of the drivers of employee engagement (Robinson, Perryman \& Hayday, 2004). Mueller and Price (1990) have stated that pay is considered to be a part of the sanction system used by the organization to motivate employees to be in compliance with its regulations and rules. Some of the predictors of turnover intention are autonomy in the job role, fair and just reward, social support, job satisfaction, organizational commitment and tenure. Harrington et al. (2001), in their study on examining the predictors of intentions to leave a job, observed that burnout at an emotional level, lower levels of intrinsic job satisfaction and dissatisfaction with salary and promotional opportunities were the main predictors.

\section{Research Objectives and Focus Issues}

The theme of employee engagement has generated a great deal of attention among many HR practitioners across the globe. It has emerged as one of the most important topics in the sphere of HRM. Organizations are increasingly focusing on means of creating and leveraging the levels of employee engagement amongst employees. Numerous studies have tried to explore the potential relations between engagement and performance-related outcome variables that suggest that enhancing engagement could create a compelling competitive advantage for organizations across the globe. Hence, the role of HPWP in enhancing employee engagement cannot be overlooked. The focus of the present study is to provide a relationship between the concept of employee engagement and implementation of HPWP within an organization to boost their levels of engagement in that organization.

The objectives of the present study are:

1. To study the impact of HPWP in terms of AMO on the levels of employee engagement of the employees.

2. To study the impact of HPWP in terms of AMO on turnover intentions.

3. To study the impact of the levels of employee engagement on their turnover intentions.

4. To determine the role of employee engagement on the relationship between HPWP and the turnover intentions of employees. 


\section{Literature Review}

Employee engagement is viewed as a practitioner's concept and has been widely written about in practitioner's journals rather than in theoretical media using empirical research. Although Robinson et al. (2004) stated that engagement results in clear business benefits, there has been surprisingly little academic and empirical research on a topic that has become so popular. Lockwood (2007) defined employee engagement as "the extent to which employees commit to something or someone in their organization, how hard they work and how long they stay as a result of that commitment." Some of the behaviours exhibited by engaged employees are belief in the organization, desire to make things better, understanding of business context and willingness to go the extra mile. Coffman and Gonzalez-Molina (2002) state that engagement is not only about how people think but, also, about how they feel and what they experience. They state that engaged employees collectively act as an "economic force that fuels an organization's profit growth." Harter, Schmidt and Hayes (2002) define employee engagement as "the individual's involvement and satisfaction with as well as enthusiasm for work." Many researchers (e.g. Buckingham \& Coffman, 1999, Harter et al., 2002) have used the term engagement to refer to employees who are involved in, enthusiastic about, satisfied with their work and, to achieve organizational goals, are willing to go the extra mile. Buckingham and Coffman (1999) stated that employee engagement includes those characteristics of a workplace environment that "attract and retain the most productive employees."

The behaviours demonstrated by the engaged employee include belief in the organization, desire to work to make things better, understanding of business context and the bigger picture, being respectful of and helpful to colleagues, willingness to go the extra mile and keeping up to date with developments in the respective field (ibid.).

As per Saks (2006), employee engagement has been defined as an emotional and intellectual commitment to the organization (Baumruk, 2004; Shaw, 2005) or the amount of discretionary effort expended by employees in their jobs. Kahn (1990) defines personal engagement as "the harnessing of organization members' selves to their work roles; in engagement, people employ and express themselves physically, cognitively, and emotionally during role performances." Kahn states that employee engagement is associated with the three psychological conditions of meaningfulness, safety and availability. High performance work systems may be described as a range of innovative HRM practices, work structures and processes which, when used in certain combinations or bundles, are mutually reinforcing and produce synergistic benefits (Huselid, 1995). These systems are built around the following core HR policy areas: (1) sophisticated selection and training; (2) behaviour-based appraisal and advancement criteria; (3) contingent pay systems; (4) job security and (5) employee involvement initiatives (Cook, 2001). HPWP are deliberately introduced either individually or in groups as bundles of practices, to improve organizational performance gradually. The synergetic impact of these practices provides additional positive outcomes beyond those that might be expected from the individual elements. At the same time, lack of congruent implementation of high performance work practices could indeed be counterproductive.

The main premise of high performance work organizations is that organizations can achieve higher flexibility, higher product quality and higher performance but, at the same time, remain cost competitive. This may be achieved by inducing workers to work harder and using the skills and information of the employees more 
effectively by moving the decision making authorities closer to those who have the relevant information. High performance work organizations are win-win systems that benefit employers but also their employees through higher wages and increased job satisfaction. The study aimed at understanding the effects of high performance organizations on the workers by investigating the effects of being involved in innovative workplace systems on job satisfaction. The results of the study conducted by Kundu and Malhan (2009) in insurance companies in India indicated that both multinational companies and Indian companies should significantly improve their practices regarding performance appraisal, training and financial benefits and HR Planning and recruitment. The HR policies of an organization can benefit employees by providing better opportunities for growth in terms of better compensation, benefits, training and development opportunities, as well as career management, in turn leading to better job satisfaction and self-fulfillment.

Boselie (2010) tried to examine HPWP in the Dutch healthcare sector, focusing on the individual employee. The results of this study suggest that the optimal choice of specific HR interventions depends on the desired outcome. When organizational citizenship behaviour is required, for example, as a result of temporary production pressure through seasonal effects (e.g. winter illnesses and seasonal influenza), HPWP that enhance the opportunity to participate are deemed to be important. This might also imply that when other HR outcomes are relevant to the organization (e.g. employee absence, stress, employee satisfaction, motivation, trust and perceived organizational justice), then different HR interventions in the AMO model should be applied in order to achieve those desired business goals. There is no single best way for HRM to increase performance. Choosing the optimal strategy depends on a number of things, including the specific organizational goals and context.
Paul and Anantharaman (2003) conducted a study on software professionals in India and found that HRM practices such as employeefriendly work environment, career development, development-oriented appraisal and comprehensive training indicated a significant positive relationship with organizational commitment. The study suggests that rigorous selection processes through written tests, programming tests and interviews help the recruiter to identify talented candidates and this process makes sure that only competent employees are identified.

In order to develop and maintain a competitive edge, the potential value of the employees of an organization should be increased by enhancing and linking their skills and capabilities in tune with the contemporary requirements of the market. At the same time, a successful combination of committed people and a benevolent organization could be a means for success for organizations in this competitive environment in India.

\subsection{Turnover Intentions}

As Holtom, Mitchell and Lee (2008) note, "... it is not surprising that turnover continues to be a vibrant field [for research] despite more than 1500 academic studies addressing the topic." Price (2001) has defined turnover as "...individual movement across the membership boundary of an organization." Turnover intention refers to an individual's perceived probability of staying or leaving an employing organization. On the other hand, Tett and Meyer (1993) state that turnover intentions are a conscious and deliberate willfulness of an employee to leave the organization. While reviewing antecedents to turnover, many studies use intent to leave rather than actual turnover as the outcome variable due to two main reasons. The first reason is that there is evidence that indicates whether workers make a conscious decision to quit before actually leaving their jobs and this relationship 
is supported by the attitude-behaviour theory (Fishbein \& Ajzen, 1975). Based on a study, it was determined that workplace and job characteristics forecast the turnover intentions (McKnight, Phillips and Hardgrave, 2009) of employees. According to Kim and Stoner (2008), the higher the level of social support and job autonomy, the lower the turnover intention; that is, there exists an inverse relationship between these variables. Paré and Tremblay (2007) have stated that non-monetary recognition, development of competencies, fair rewards, quick information sharing practices and clear and transparent communications are negatively related to turnover intentions. As per Albrecht (2006), organizational justice, job autonomy, organizational support, trust in management and job satisfaction influence turnover intention. Hemdi and Nasurdin (2006) stated that just and structured performance appraisal of employees reduces turnover intentions. Research studies investigating social factors such as the transformational leadership of supervisors (vertical relationships) and surface-level similarities between peers (horizontal relationships) are also an antecedent of employeeturnover intention (Dupré \& Day, 2007). Employee perceptions of management and trust have a significantly inverse impact on turnover intentions (Alexandrov, Babakus \& Yavas 2007, Albrecht, 2006).

\section{Research Methodology}

Based on the fact that the research was exploratory in nature, it was ex post facto and was conducted on the basis of self-completed questionnaires and secondary sources, such as journals, statistical handbooks, reports and information sourced from the internet. Primary data was collected from employees working in PSUs in Delhi and NCR through administered questionnaires. The questionnaire sought to assess the impact of HPWP on employee engagement and turnover intentions. The data was collected from 104 employees working in PSUs. The respondents were approached and interviewed personally for their responses. The descriptive statistics of the data are given in Table 1.

Table 1.

\begin{tabular}{lccccc}
\hline Variable & N & Minimum & Maximum & Mean & Standard Deviation \\
\hline Ability & 104 & 39.0 & 73.0 & 55.0 & 6.43854 \\
Motivation & 104 & 35.0 & 62.0 & 47.7 & 5.59780 \\
Opportunity & 104 & 18.0 & 38.0 & 28.6 & 4.38758 \\
Employee Engagement & 104 & 18.0 & 33.0 & 24.5 & 2.98215 \\
Turnover Intentions & 104 & 5.0 & 19.0 & 11.4 & 3.68878 \\
\hline
\end{tabular}

Table 1: Descriptive Statistics; source: Original Research

\section{Analysis and Interpretation}

The reliability analysis for questions pertaining to ability, motivation, opportunity to participate, employee engagement and turnover intentions was conducted by calculating Cronbach's Alpha, which yielded acceptable results. In the case of ability, questions such as opportunities for skill development being available in the organization, management encourages employees to undergo specialized technical courses, selection process tries to judge the candidate's ability to collaborate and work in teams and employees are provided with performance-based feedback and counseling after the appraisal was completed.

In case of motivation, variables included the rewards that I receive are fair in comparison to 
my contribution to the organization, employees in my company are eligible for cash bonuses based on individual or company performance, pay increases received in the last two years adequately reflect recent performance evaluations, employees in the company can expect to stay in the organization for as long as they do good work and employees are regularly informed of their work unit's performance. For opportunity to participate, variables such as the company supports team development and training, development of teams is an important element of the company's corporate strategy and employees are free to invest in new materials and technology were used.

For employee engagement, receiving praise or recognitions at work highly motivates me, at work my opinion seems to count which makes me go the extra mile and I work too hard considering my outcomes were some of the variables involved. In the case of turnover intentions, variables such as I frequently think of quitting my job, I am planning to search for a job during the next 12 months and I would prefer a company with a higher package but a less challenging job profile were used.

\begin{tabular}{lccccc}
\hline & Ability & Motivation & Opportunity & $\begin{array}{c}\text { Employee } \\
\text { Engagement }\end{array}$ & $\begin{array}{c}\text { Turnover } \\
\text { Intentions }\end{array}$ \\
Ability & - & $0.538\left(0.000^{* *}\right)$ & $0.606\left(0.000^{* *}\right)$ & $0.381\left(0.003^{* *}\right)$ & $-0.178(0.174)$ \\
Motivation & $0.538\left(0.000^{* *}\right)$ & - & $0.654\left(0.000^{* *}\right)$ & $0.485\left(0.000^{* *}\right)$ & $-0.003(0.982)$ \\
Opportunity & $0.606\left(0.000^{* *}\right)$ & $0.654\left(0.000^{* *}\right)$ & - & $0.412\left(0.001^{* *}\right)$ & $-0.108(0.412)$ \\
Employee Engagement & $0.381\left(0.003^{* *}\right)$ & $0485\left(0.000^{* *}\right)$ & $0.412\left(0.001^{* *}\right)$ & - & $-0.197(0.132)$ \\
Turnover Intentions & $-0.178(0.174)$ & $-0.003(0.982)$ & $-0.108(0.412)$ & $-0.197(0.132)$ & - \\
\hline
\end{tabular}

Table 2: Construct Correlation Matrix; source: Original Research $\left(n=60 ;{ }^{* *}=\right.$ significant at the 0.01 level)

The results obtained indicate that there is a moderate degree of correlation between the ability, motivation and opportunity to participate components of the AMO model of HPWP. This indicates that the three components are not independent of each other. These results allow us to draw the conclusion that investment in one component of the AMO model (e.g. in skillenhancing HRM practice, like training) stimulates the levels of other components of the AMO model of HPWP. This in turn shows that there is a moderate degree of correlation between ability, motivation and opportunity to participate components of AMO model and employee engagement for employees in PSUs. It was also seen that there was a negative, though weak to moderate correlation between ability, motivation, opportunity to participate and employee engagement, that is, as the levels of employee engagement and HPWP implementation in terms of ability, motivation and opportunity to participate increases, turnover intentions of an employee decreases. Amongst these, ability and employee engagement have relatively stronger degrees of correlation with turnover intentions. This could be due to the fact that as the opportunities for skill development in the organization increases, encouragement is provided by management to employees to undergo specialized technical courses, selection processes in the organization are fair and rigorous and so on, so that the employee feels more satisfied and confident in the organization, thereby resulting in a declining intention to leave the organization. Also, as far as PSUs are concerned, there is a high level of job security amongst the employees, resulting in relatively low turnover intentions. In addition, in any 
organization, there could be multiple other reasons for attrition, such as challenging job roles, supervisor support and organizational support.

\subsection{Confirmatory Factor Analysis}

The confirmatory factor analysis (CFA) was conducted using Amos 18.0. The CFA helped to identify those manifest variables which, in the minds of the public sector employees with regards to ability, motivation, opportunity to participate, employee engagement and turnover intentions were of utmost importance. The CFA helped establish the measurement model which had a good fit. The interpretation of fit indexes allowed for the selection of a theoretical model that corresponded to the factorial structure that best fits the empirical data for the employees of PSUs.
The fit indexes used were the ratio of chi-square to degrees of freedom $\left(\mathrm{X}^{2} / \mathrm{df}\right)$, goodness of fit (GFI), adjusted goodness of fit (AGFI) and the root mean square residual (RMR).

The CFA, with all the manifest variables and latent variables taken into consideration, produced a low GFI. Thus, values of squared multiple correlations which explain the total amount of variance a measured variable has in common with the construct upon which it loads or the variance explained in a measured variable by the construct were checked and those manifest variables having a value less than 0.5 on average were dropped. The result for the final model was chi-square, $X^{2} / \mathrm{df}$, GFI, AGFI and RMR was $309.021,2.51,0.768,0.678$, and 0.091 respectively (Figure 1).

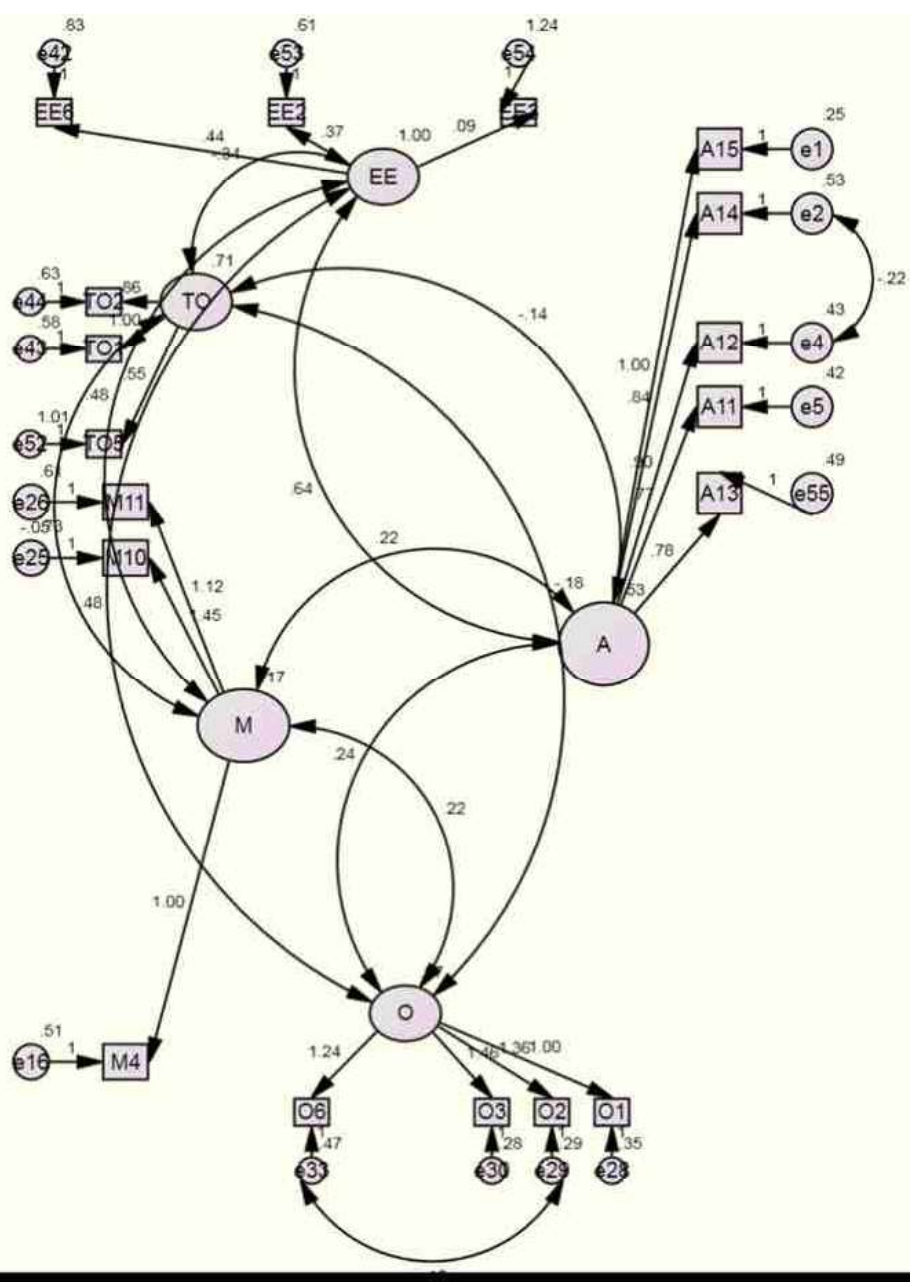

Figure 1: Confirmatory Factor Analysis Results; source: Original Research 
From the CFA measurement model, important manifest variables were observed (see Table 3 ). These measured variables should be duly considered by the PSU senior management when attempting to strategize for increased employee engagement and decreased turnover intentions.

It is interesting to note that for manifest variables, such as whether employees have faith in the performance appraisal system, that the appraisal system in the company is development and growth oriented, teamwork orientation is one of the most important parameters for performance evaluation, the company supports team development and training, if I have my own way, I will be working for this company one year from now and performance of the employees is measured on the basis of objective, quantifiable factors have a high factor loading, so the management should be cognizant of this and continue to maintain focus on these manifest variables.

On obtaining the solution through the measurement model, that is, CFA, for the purpose of testing and estimating causal relations and the hypothesis, the structural model was considered. It helped develop a hybrid model with multiple indicators or manifest variables for each latent variable or construct and paths specifying the beta coefficient connecting the latent variables. This would be of help to senior management in understanding the mind set and perspectives of prospective employees. The fit indices of the structural model were chi-square, $\mathrm{X}^{2} / \mathrm{df}$, GFI, AGFI, RMR and RMSEA was $347.59,2.75,0.754,0.666$, and 0.136 , respectively (Figure 2).

Thus, from the structural model, the $\mathrm{p}$ value and standardized regression weight or beta value connecting the latent variables was calculated, which helps in accepting or rejecting the developed hypothesis. The hypothesis for ability to employee engagement, ability to opportunity to participate and motivation to opportunity to participate were accepted with a beta value of $0.885,0.386$ and 0.832 . This establishes the fact that, in PSUs, improving ability leads to increased employee engagement and motivation of employees leads to increased opportunity to participate on the part of the employees. Senior management should be cognizant of this fact and accordingly strategize to maximise employee engagement. 
Manifest Variable

Ability

Employees have faith in the performance appraisal system

The appraisal data is used for making decisions like job rotation, promotion, training and compensation.

Appraisal system in my company is development and growth oriented.

Performance of the employees is measured on the basis of objective and quantifiable factors

Employees are provided performance based feedback and counseling after the appraisal.

\section{Motivation}

The pay increases and/or bonuses I have received in the last 10 years adequately reflect my recent performance evaluations

The findings from employee surveys are communicated to the employees of my company.

Employees are regularly informed of the criteria that will be included in their performance evaluation.

\section{Opportunity to participate}

The development of teams is an important element of my company's corporate strategy.

My company supports team development and training

Teamwork orientation is one of the most important parameter for performance evaluation

My company encourages employees to be creative, innovative and do new things

\section{Employee Engagement}

I give a great deal of time and attention to the organization but do not feel appreciated

At work my opinion seems to count which makes me go the extra mile

The satisfaction that I receive from my pay and job makes me put in extra effort in my work

Turnover Intentions

I frequently think of quitting my job

TO1

If I have my own way, I will be working for this organization 1 year from now

Higher incentives offered another company could make me change my job

Factor Loading

$(\lambda)(p<0.001)$

A15

A14

0.643

A12

0.707

A11

0.654

A13

0.629

M4

M10

M11

0.513

01

0.658

$\mathrm{O} 2$

0.797

O3

06

0.683

EE6

EE2

EE3

0.085

Table 3: Important Manifest Variables from the CFA; source: Original Research 


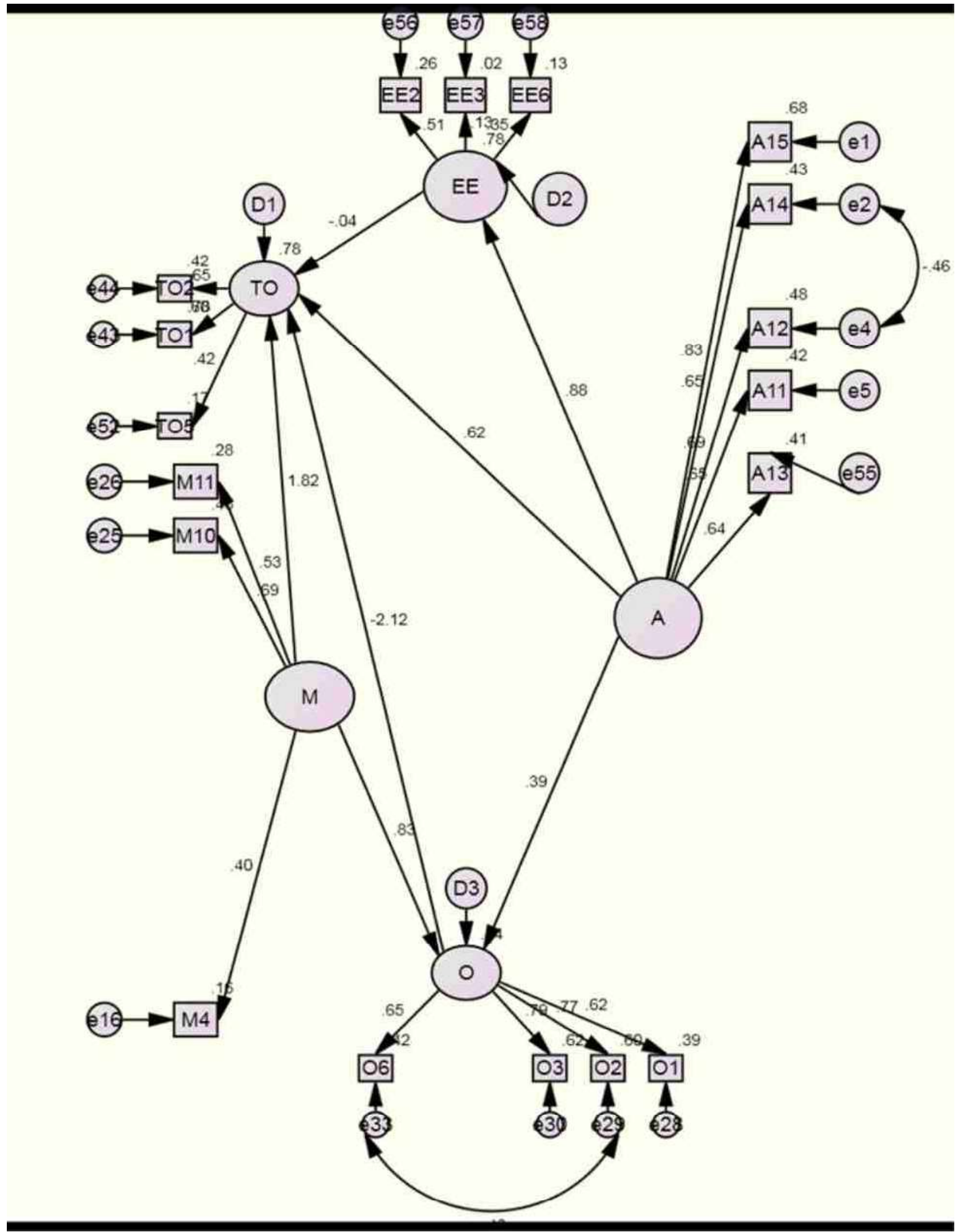

Figure 2: The Structural Model; source: Original Research 


\section{Conclusion}

The present study seeks to examine the impact of a multidimensional set of HPWP on turnover intentions among employees working in PSUs in the NCR region. The impact of the intervening variable, employee engagement, would also be included in the analysis. The direction and strength of the correlation analyses lends support to the notion that HPWP, in terms of the AMO model, have an additive, positive relationship with employee engagement. Thus, the study supports the findings of prior work that firms that implement HPWP will generally have more engaged employees. With regards to the correlation between HPWP (AMO model), employee engagement and turnover intentions, the correlation is negative.

CFA was conducted to help verify the proposed structure for the HPWP, employee engagement and turnover intentions scales. The CFA helped to identify those manifest variables which in the minds of the employees working in PSUs were of utmost importance. With regards to the ability dimension of HPWP, the employees have faith in the performance appraisal system, are concerned that the appraisal is development and growth oriented and the data is used for making decisions like job rotation, promotion, training, and compensation. Performance of employees is measured on the basis of objective and quantifiable factors and that feedback and counseling is provided after the appraisal. In terms of motivation, information gathered from variables such as whether employees feel that the pay increases and/or bonuses that they have received in the last ten years adequately reflect their recent performance evaluations, findings from employee surveys are communicated to us and employees are regularly informed of the criteria that will be included in their performance evaluation, have been found to be relevant. In terms of opportunity to participate, employees consider the development of teams as an important element of the company's corporate strategy and that it is an important parameter for performance evaluation. At the same time, employees feel it is necessary that the company encourages employees to be creative, innovative and do new things. In terms of employee engagement, it is of the utmost importance that employees feel that their opinion counts at work, which is what makes them go the extra mile. The satisfaction that they derive from pay and the nature of their work can make them put in extra effort at work.

The structural model helps to establish the fact that, in PSUs, improving ability leads to increased employee engagement, while motivation of employees leads to increased opportunity to participate on the part of the employees. Consequently, senior management should be cognizant of these facts and accordingly strategize to maximise employee engagement.

\subsection{Limitations}

There are some limitations to this research that can be identified and possibly addressed in the future. To begin with, the research for assessing the levels of employee engagement was provided out by the respondents themselves rather than being directly observed. Consequently, differences between an individual's self-reporting and direct observation in the case of perceptions of HPWP, employee engagement levels and turnover intentions could exist. As a result, other modes, such as first hand observation, assessment by colleagues and other similar modes, could be considered for other research studies. This would assist in reducing the fallout from self-assessment to a minimum. Further, another limitation of the present research is that the study was conducted only for the Delhi and NCR region and so the results of the study cannot be generalized. Finally, the nature of research is cross sectional and does not take into account whether the perception of HPWP, employee engagement and turnover intentions change over a period of time. A longitudinal survey might be conducted to examine this issue. 


\section{References}

Albrecht, S. (2006). Predictors of Employee Extra-Role Performance and Turnover Intentions in the Public Sector: An Integrated Model, International Journal of Human Resource Development \& Management, 6, 263-278

Alexandrov, A., Babakus, E. and Yavas, U. (2007). The Effects of Perceived Management Concern for Frontline Employees and Customers on Turnover Intentions, Journal of Service Research, 9, 356-371.

Appelbaum, E., Bailey, T., Berg, P. and Kalleberg, A. (2000). Manufacturing Advantage: Why HighPerformance Work Systems Pay Off, Ithaca, NY: Cornell University Press.

Arthur, J.B. (1994). Effects of Human Resource Systems on Manufacturing Performance and Turnover, Academy of Management Journal, 37(3), 670-687.

Bailey, T., Berg, P. and Sandy, C. (2001). The Effect of High-Performance Work Practices on Employee Earnings in the Steel, Apparel, and Medical Electronics and Imaging Industries, Industrial Labor Relations Review, 54(2A), 525-543.

Baumruk, R. (2004). The Missing Link: The Role of Employee Engagement in Business Success, Workspan, 47, 48-52.

Boselie, P. (2010). High Performance Work Practices in the Health Care Sector: A Dutch Case Study, International Journal of Manpower, 31(1), 42-58.

Boxall, P. and Purcell, J. (2003). Strategy and Human Resource Management, Basingstoke: Palgrave Macmillan.

Buckingham, M. and Coffman, C. (1999). First, Break All the Rules: What the World's Greatest Managers do Differently, New York, NY: Simon \& Shuster.

Chang, J. (2006). Rules of Engagement, Sales and Marketing Management, 158(3), 18.

Coffman, C. and Gonzalez-Molina, G. (2002). Follow This Path: How the World's Greatest Organizations Drive Growth by Unleashing Human Potential, New York, NY: Warner Books, Inc.

Combs, J., Liu, Y., Hall, A. T. and Ketchen, D. (2006). How Much Do High Performance Work Practices Matter? A Meta-Analysis of Their Effects on Organizational Performance, Personnel Psychology, 59(3), $501 ? 528$.

Cook, F.L. (2001). Human Resource Strategy to Improve Organizational Performance: A Route for Firms in Britain? International Journal of Management Reviews, 3, 321-339.
Crawford, N. (2006). Managing Employment Engagement, Canadian Manager, 31(1), 17-18.

Dupré, K. E. and Day, A. L. (2007). The Effects of Supportive Management and Job Quality on the Turnover Intentions and Health of Military Personnel, Human Resource Management, 46, 185-201.

Echols, M.E. (2005), Engaging Employees to Impact Performance, Human Capital, February, 44-8.

Fishbein, M. and Ajzen, I. (1975). Belief, Attitude, Intention and Behavior: An Introduction to Theory and Research, Cambridge, MA: Addison-Wesley Pub. Co.

Harrington, D., Bean, N., Pintello, D. and Mathews, D. (2001), Job Satisfaction and Burnout: Predictors of Intentions to Leave a Job in a Military Setting, Administration in Social Work, 25(3), 1-16.

Harter, J.K., Schmidt, F.L. and Hayes, T.L. (2002). Business-Unit-Level Relationship between Employee Satisfaction, Employee Engagement, and Business Outcomes: A Meta-Analysis. Journal of Applied Psychology, 87(2), 268-279.

Hemdi, M. A. and Nasurdin, A. M. (2006). Predicting Turnover Intentions of Hotel Employees: The In?uence of Employee Development Human Resource Management Practices and Trust in Organizations, Gadjah Mada International Journal of Business, 8(1), 21-42.

Holtom, B., Mitchell, T. \& Lee, T. (2008). Turnover and Retention Research: A Glance at the Past, a Closer Review of the Present, and a Venture into the Future, Academy of Management Annals, 291, 231-274.

Hoque, K. (1999). Human Resource Management and Performance in the UK Hotel Industry, British Journal of Industrial Relations, 37(3), 419-443.

Huselid, M.A. (1995). The Impact of Human Resource Management Practices on Turnover, Productivity, and Corporate Financial Performance, Academy of Management Journal, 38, 635-672.

Joshi, R. J. and Sodhi, J. S. (2011). Drivers of Employee Engagement in Indian Organizations, The Indian Journal of Industrial Relations, 47(1), 162-182.

Kahn, W.A. (1990). An Exercise of Authority, Organizational Behavior Teaching Review, 14(2), 28-42.

Kim, H. and Stoner, M. (2008). Burnout and Turnover Intention among Social Workers: Effects of Role Stress, Job Autonomy and Social Support, Administration in Social Work, 32(3), 5-25.

Kundu, S.C. and Malhan, D. (2009). HRM Practices in Insurance Companies: A Study of Indian and Multinational Companies, Managing Global Transitions, 7(2), 191-215. 
Lepak, D.P., Liao, H., Chung, Y. and Harden, E.E. (2006). A Conceptual Review of Human Resource Management Systems in Strategic Human Resource Management Research, in Martocchio, J.J., ed., Research in Personnel and Human Resource Management, 25, 217-271

Lockwood, N. (2007). Leveraging Employee Engagement for Competitive Advantage: HR's Strategic Role. HR Magazine. 52(3), 1-11.

Luthans, F. and Peterson, S.J. (2002). Employee Engagement and Manager Self-Efficacy: Implications for Managerial Effectiveness and Development, Journal of Management Development, 21(5), 376-387.

McKnight, D.H., Phillips, B. and Hardgrave, B.C. (2009). Which Reduces IT Turnover Intention the Most: Workplace Characteristics or Job Characteristics? Information and Management, 46, 167-174.

Mueller, C.W. and Price, J. (1990). Economic, Psychological, and Sociological Determinants of Voluntary Turnover, Journal of Behavioral Economics, 19, 321-336.

Paré, G. and Tremblay, M. (2007). The In?uence of HighInvolvement Human Resources Practices, Procedural Justice, Organizational Commitment, and Citizenship Behaviors on Information Technology Professionals' Turnover Intentions, Group and Organization Management, 32, 326-357.

Paul, A.K. and Anantharaman, R.N. (2003). Impact of People Management Practices on Organisational Performance, International Journal of Human Resource Management, 14(7), 1246-66.

Price, J. (2001). Reflections on the Determinants of Voluntary Turnover, International Journal of Manpower, 22, 600-624.
Price, J. \& Mueller, C.W. (1981). A Causal Model of Turnover for Nurses, Academy of Management Journal, 24, 543-565.

Robinson, D., Perryman, S. and Hayday, S. (2004). The Drivers of Employee Engagement, Brighton: Institute for Employment Studies.

Saks, A.M. (2006). Antecedents and Consequences of Employee Engagement, Journal of Managerial Psychology, 21(7), 600-619.

Shaw, K. (2005). An Engagement Strategy Process for Communicators, Strategic Communication Management, 9(3), 26-29.

Smythe, J. (2008). Engaging Employees to Drive Performance, Communication World, 25(3), 20-22.

Tasker, J. (2004). Engagement Equals Productivity. Personnel Today, October 5th, 8-9.

Tett, R.P. \& Meyer, J.P. (1993). Job Satisfaction, Organizational Commitment, Turnover Intention and Turnover: Path Analysis Based on Meta Analytic Findings, Personnel Psychology, 45(2), 259-293.

Tritch, T. (2003). B and Q Boosts Employment Engagement - and Profits, Gallup Management Journal, May 8 th, 1.

Walters, D. (2008). How I Made a Difference: Employee Engagement, Personnel Today, September 23rd, 33.

Way, S.A. (2002). High Performance Work and Intermediate Indicators of Firm's Performance within the US Small Business Sector, Journal of Management, 28, 765-785.

Wright, P.M., McMahan, G.C. and McWilliams, A. (1994). Human Resources and Sustained Competitive Advantage: A Resource Based Perspective, International Journal of Human Resource Management, 5, 301-326.

Zacharatos, A., Barling, J. and Iverson, R. (2005). High Performance Work Systems and Occupational Safety, Journal of Applied Psychology, 9(1), 77-93. 